PROBLEMS

OF EDUCATION

IN THE $21^{\text {st }}$ CENTURY

Vol. 76, No. 3, 2018

406

EDUCATION BY INFORMAL EDUCATORS

\author{
Sara Zamir \\ Achva Academic College and Ben Gurion University at Eilat, Israel \\ E-mail: sarahz@bgu.ac.il
}

\begin{abstract}
Discussion about the need for professionalization has accompanied the development of informal education from its very early stages. Some people believe informal education is staffed by temporary players whose main value derived in part from the fact that their work embodies the principles of altruism, hence they need no professional training. In contrast, others believe that work in this field is complex, hence appropriate training settings should be set up for those working in informal education as well.

The aim of this research was to evaluate the perception of formal education by informal education educators.

The research methodology is qualitative; it employs a structured interview of the participants and a semiotic analysis of pictures that participants were asked to provide that they felt represented the formal education system.

The main findings of the semiotic analysis clearly show that the pictures chosen raise connotations of rigidity, emptiness, loneliness, sadness, insufficiency and boredom.

Those images are strongly connected to the debate of recruiting resourceful and capable teachers to formal education systems in the era of accountability.
\end{abstract}

Keywords: formal education, informal education, informal code, semiotics.

\title{
Introduction
}

In professional literature dealing on informal education it is hard to find a single definition that is widely-accepted by scholars. There is a gap between the considerable amount of activity in this field and the paucity of related scholarship and conceptualization (Romi, 2009). Moreover, the field is both complex and multi-dimensional and many scholars have concluded that the very attempt to define informal education defies its unique essence (Romi \& Shmeida, 2007a). The names given to this field derive from how they relate to formal education: "informal education", "non-formal education"; and in a positive vein: "supplementary education" "alternative education", "extra-mural education", "extra-curricular activities" and "social-community education".

There is a distinction between three areas of education: "formal education", which is defined as education at school; "non-formal education", which is defined as a process that takes place without any institutionalized setting, but is rather the random daily encounter with the environment that offers experiences through which a person acquires knowledge, skills, opinions and insights, and "informal education", which is defined as a set of planned educational activities that take place outside regular school hours and usually outside the school premises (Coombs \& Ahmed, 1994).

The purpose of informal education is to complement and supplement the formal system and help youngsters reach spiritual, religious and political maturity as well as to instill them with suitable behaviors for leisure time activities (Romi \& Shmeida, 2007b). The informal settings usually have unique dimensions such as voluntarism, symmetry, moratorium and peer supervision (Kahana, 1974). In addition, there are types of organizational frameworks within 
informal education depending on the level to which they are supervised (Kahana, 1974, 1975). Youth houses and clubs are highly supervised by adults; these adults try to defuse tensions among the youngsters. In contrast, there are youth houses where the level of supervision is also high but unlike the above, they try to load the youngsters with new resources and instill the values of a particular movement. Another type of framework is those settings where the level of supervision is low. This would include groups involved in leisure activities that do not produce resources and it is doubtful whether the title "educational setting" is truly apt. This would refer to street gangs or spontaneous settings for a one-off purpose or task at school or in the residential neighborhood.

Many scholars have discussed the question of the purpose of informal education. At the systemic level, it is meant to act as a mechanism of change for the formal education system and to prevent, or at least moderate, processes of fossilization and fixation within it (Keller, 1996). At the level of the individual, informal education is meant to develop the youngsters' sense of empowerment and self-esteem (Romi \& Shmeida, 2007b). Another purpose is to educate the youth to play social roles, both as leaders and as regular citizens (Gal, 1985). In terms of pedagogical approach, the difference between formal and informal education lies in the fact that informal education is not based on fixed curricula and is not controlled by a timetable, exams, teaching delivered by professional teachers, but rather is considered as a life-long learning process based on changing conditions where teaching is perceived as a negotiation between the instructor and the learners or between the learners themselves (Romi \& Shmeida, 2007c). Its purpose is to create a subjective, emotional learning experience that may be bound to cognitive content. Teaching and learning in informal education are not the main point of the encounter but rather are a by-product of it. Another difference is the perception of time. In informal education, the process is not connected in any way to a fixed, measurable timetable, and in terms of venue there is also no limitation and activities may take place in a variety of locations. A unique section of informal education is that of "extra-curricular activities". These activities may be supervised and sponsored by the school and so are termed "semi-informal education". Schools are based on the division of work and specializations and they are limited in their ability to handle contemporary problems in shaping the young person's complete personality (Romi \& Shmeida, 2007c).

\section{The Informal Code}

It is customary to use the concept of "informal code" in this field, and so we will first define what a code is. A "code" is a set of explicit social conventions through which the unknown is converted into the known (Kahana, 2007). The main difference between formal and informal organizations lies not in their purpose or functioning, but in the nature of their underlying codes of behavior (Kahana, 2007).

Studies in this field have identified eight components of the informal code (Kahana, 2007): (1) volunteerism- the free choice to join the framework, leave it or act within it, all of which requires the development of value-laden commitment and strengthening of the youngsters' negotiations with the adult world. In other words, the activity must be attractive and must match the youngsters' areas of interest. (2) Multi-dimensionality - plenty of room for a variety of activities and skills, which will interest a large number of participants according to their personal preferences and tendencies (dance, sports, camping). (3) Symmetry - interactions based on equality and reciprocal matching of principles and expectations without imposing them on either side. (4) Dualism - the simultaneous existence of several trends such as competition and cooperation, which enables the experiencing of contradictory patterns of behavior. (5) Moratorium - room for trial and error, which enables experiencing a wide range of roles and tasks. (6) Modularity - the ability to improvise and benefit from situational opportunities. (7) Expressive instrumentality - a combination of activities with immediate compensation that is mostly demonstrative and productive activity directed towards obtaining results. This 
Sara ZAMIR. Appraising the image of formal education by informal educators

PROBLEMS

OF EDUCATION

IN THE $21^{\text {st }}$ CENTURY Vol. 76, No. 3, 2018

408

component augments the attraction and the degree of influence the activity has on the student. (8) Pragmatic symbolism - attribution of symbolic meaning to activity or turning symbols into actions, thereby reinforcing identification with the symbol.

There is reciprocity between the various components; hence, for example, multidimensionality contributes to symmetry since it enables participants to express themselves according to their talents and the moratorium contributes to the expressive instrumentality through the space it allows for experimentation.

According to Lampert (2009), in recent years we have been witnessing a certain reconciliation between the formal and the informal; many schools are adopting "informal" teaching methods which are given names such as "experiential learning" or "learning outside the classroom". At the same time, outside school in the informal world, there are many initiatives designed to "improve scholastic achievement" or to fight dropout, anxiety and violence.

Research aim: To evaluate the image of formal educators by informal educators.

Research question: How do informal educators perceive the realm of formal education?

\section{Methodology of Research}

\section{General Background}

The method in use is the qualitative method. Among the many advantages of qualitative methods, one should mention the evidences that qualitative research provides. This method allows content evaluation with detail and attitude explanations become conceivable. Qualitative methodology combines a systemic drawing of valid conclusions derived from the participants' answers (the "text") and is based on the understanding and interpretation of the researcher (Sabar Ben -Yehoshua, 2006). The research took place during 2014-6.

\section{Sample}

The research sample included 13 educators, between the ages of thirty and forty, with at least two years of experience in the field of informal education from various frameworks in a city in the south of Israel. The main limitation of this research lies in the very selection of the research participants; since the nature of this research demanded frankness as well as truthfulness, only a limited number of the research participants agreed to collaborate, and their anonymity of the sample was kept.

\section{Instruments and Data Analysis}

Research tools:

A. Structured interview

Interview questions:

The interview began with an open question:

1. Tell me about your professional background.

2. *For teachers who demonstrated no prior history in formal education: If you had the necessary qualifications to work in the formal education system, would you consider doing so?

*For the research participants with prior experience in the formal education:

Have you considered returning to teach in the formal system?

B. If I asked you to take a photo of the concept of informal education, what do you think you would take a picture of? Describe the imaginary picture as accurately as possible.

Photograph and semiotic analysis - the research participants were asked to show a photo we would then analyze with semiotic tools. The picture was initiated by the subject and thus it 
required of us thought and initiative or another way to search in the data base for an existing picture that would represent the concept for them. This option was given at the request of several of the subjects. A semiotic analysis is a process of reconstructing the image that has been semanticized, or by adding intellect to the object. Semiotics developed out of the research field of structural linguistics which originated in the studies of Swiss linguist Ferdinand de Saussure (Hebrew version 2005). This approach saw language as a system. De Saussure (2005) proposed a simple model of a signifier - in this study the subject's photograph or the picture chosen - and the signified - the concept or idea (in this study: the concept of "formal education"). While de Saussure allocated a special place for linguistics within semiology, Barthes preferred to see semiology as part of linguistics, since he saw the system of signs as requiring the mediation of language, which extracts their signifiers and names what is being signified. Barthes distinguishes between the kinds of knowledge required: at the first level - denotation - the reader needs basic linguistic and anthropological knowledge. At the second level - connotation - the reader needs other kinds of cultural knowledge. The act of reading the picture is a constructive process.

\section{Results of Research}

\section{Representative Responses to the Question of Professional Background}

All the participants without exception reported that they came to informal education from some experience in the field and that they experienced great satisfaction with this activity. Examples:

"About five years ago I began to work at the Jewish Agency on a project called "Starting a future", a project you undertake ... I worked with youth in middle school ... you take on yourself 16 youngsters you are their trustee, responsible for them from the moment they open their eyes"

"... in the past year in Tel Aviv at the Acting School, and suddenly at the same time I had the urge to work with youth, it's just ... Something suddenly awoke in me that really brought me back to life"

"When I was released from the army I came to the community center looking for casual work - I worked at an afternoon center and gradually I advanced and became a youth coordinator. During this time I learned therapeutic diagnostics, and early education movement and music at Wingate- Academy for sport instructors, massage for infants and later to be a soldier-teacher for youth advancement ... you understand that you can make a difference to the youth and you can make a difference to a child's life at the highest resolution ... it happens that at school kids are disconnected and don't understand and then in the afternoon I see students and am able to reach them more successfully. We manage to make them want to study and succeed perhaps precisely because it is informal. They make a change."

Representative responses to the question of moving/returning to teach in the formal education system:

"I don't know how I would cope in the formal system, because I think it is very limited and it does not enable you to fully give of your abilities. I very much need a framework, but I need to have the freedom to act within it so that I can really give all my knowledge and experience and what I have to give and that is what the informal framework allows"

"It's really good where I am. I feel the best in the world here and I really think that working in informal education is meaningful, right and important. And it is important for people like us to be there"

"Of course not. I have now, and I will never try. I would go and sell clothes. I don't believe in what goes on at school. 
Sara ZAMIR. Appraising the image of formal education by informal educators

PROBLEMS

OF EDUCATION

IN THE $21^{\text {st }}$ CENTURY

Vol. 76, No. 3, 2018

410
Findings from the Representative Pictures and Their Respective Semiotic Analysis

Table 1. Informal educators' perception of the formal education through the eye of a camera or a picture taken from a database.

\begin{tabular}{rll}
\hline Pictures & Denotation (what's in the picture) & Signification \\
& $\begin{array}{ll}\text { Signpost } \\
\text { Stop sign } \\
\text { Red and white }\end{array}$ & Stopping \\
Existing picture & Warning
\end{tabular}

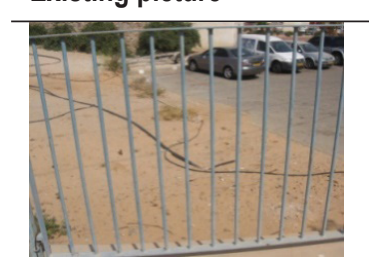

A fence marking the boundary around sand.

No way out

Closed

No people or students

Need to break through boundaries

Subject's picture

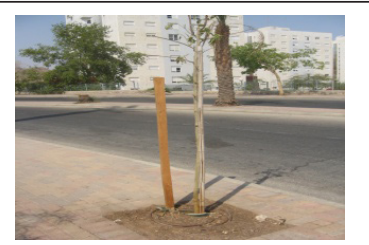

Bare tree

Supporting pole, for from the trunk and very slender

Lack of support

No fruit

Bare

Alone and sad

Subject's picture

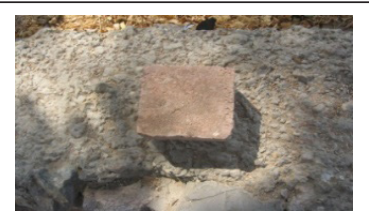

Square stone

lying on rock

Fixation

Being square

Lack of creativity

Subject's picture

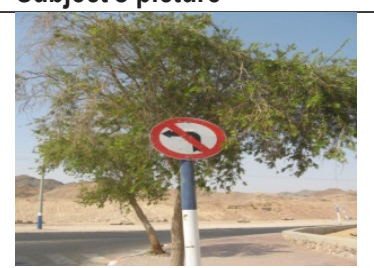

No left turn

Signpost. Behind it a big green tree

Limitation. One has only one way - the right turn.

Control, Obedience, Constrain.

Close up picture

Adult finger

Subject's picture

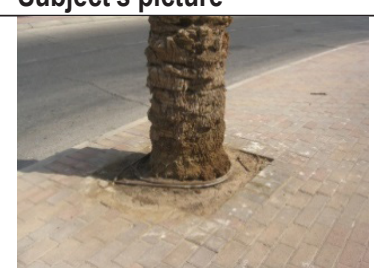

Tree trunk

Hosepipe around it

Drip irrigators

A single tree

Loneliness Closing in on the tree. Irrigating but also strangling. No fruits 

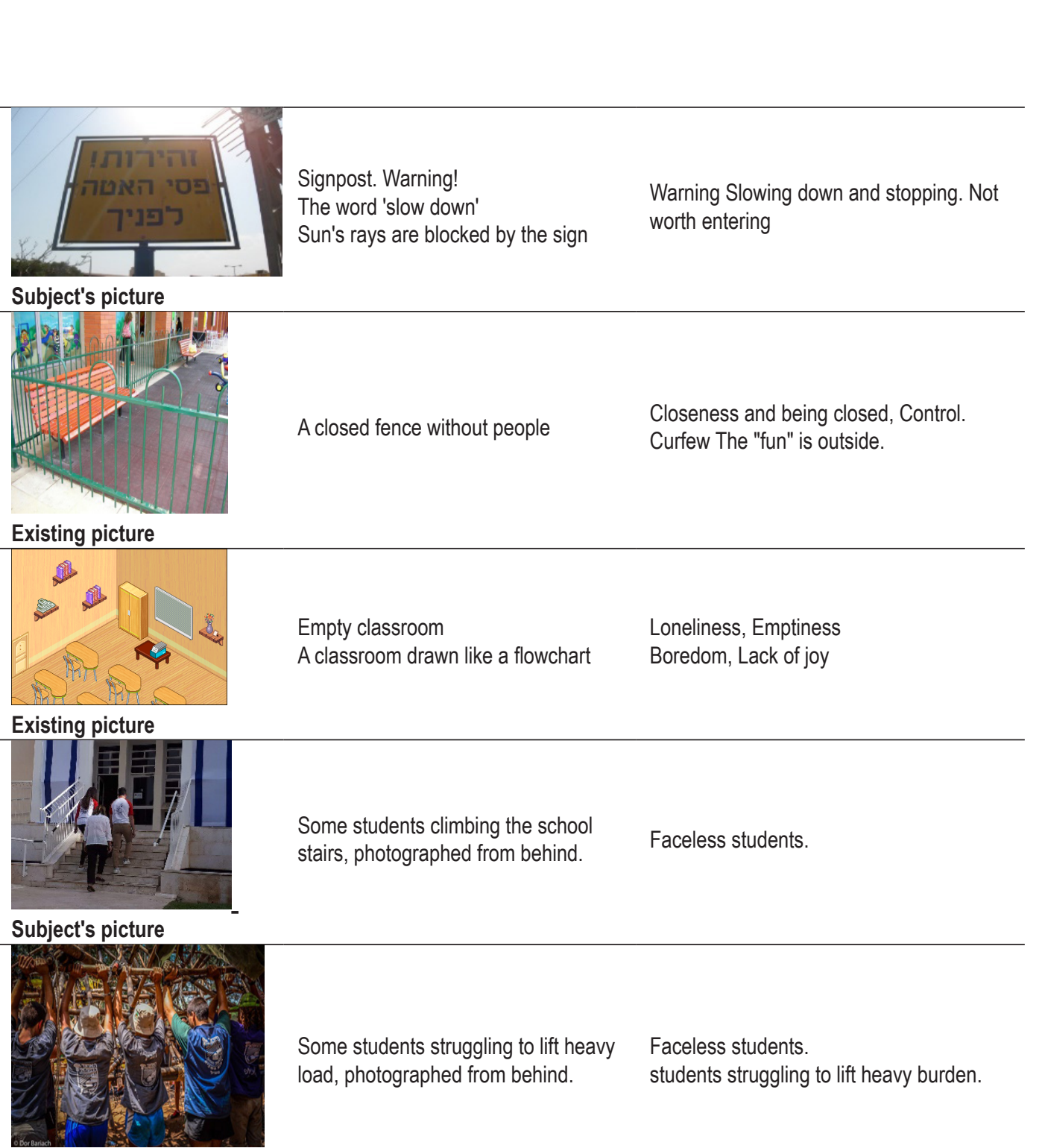

Some students struggling to lift heavy load, photographed from behind.
Faceless students.

students struggling to lift heavy burden.

Subject's picture

$\begin{array}{ll}\text { Empty classroom. } & \begin{array}{l}\text { Loneliness, Emptiness Boredom, Lack } \\ \text { of joy. }\end{array} \\ \text { Subject's picture } & \end{array}$

The semiotic analysis clearly shows that the pictures chosen raise connotations of rigidity, emptiness, loneliness, sadness, insufficiency and boredom.

\section{Discussion}

The opening question in this research referred to the professional background of the informal educators. All the participants without exception testified that they came to informal education because of some experience they had encountered in this field and that they experienced great satisfaction with their work. Phrases such as "something suddenly awoke in me that really 
PROBLEMS

OF EDUCATION

IN THE $21^{\text {st }}$ CENTURY Vol. 76, No. 3, 2018

412

brought me back to life" are explained by the unification theory (Dewey, 1960) which deals with the unification between education and real life. Unification theory claims that formal education goes beyond the confines of the school premises and makes life skills accessible. Informal education, according to this theory, is more meaningful for daily life. Dewey suggests a balance between the realm of the random-informal and the intentional-formal. In his opinion it is important to make a connection between the acquisition of knowledge and expertise that is technical and the formation of the social spirit. Accordingly, it seems that informal study programs are seen by the participants as relevant to life as opposed to the material studied at school, which they mostly perceive as detached from reality. The participants declare that informal education takes an active role in the social environment that is relevant to the present while formal education deals almost entirely with imparting knowledge.

In the current research, the subjects were asked whether they would, if they had the right qualifications or if it were possible, move into formal education. Most of them responded in the negative, including two subjects who had the necessary formal training to do so. Despite their educational qualifications, they both stated that they chose informal education. Subjects who were considering approaching the formal system following the above question expressed reservations about their dilemma and said they were not sure they would last there. In their opinion, informal education, in accordance with Kahana's (1997) structural sociology approach, is a unique educational method characterized by principles of behavior that have different codes from those of formal education. The principles are a meeting point between the interests of the youth and the interests of society. Informal education has greater potential to achieve educational goals that formal education has difficulty achieving by creating an atmosphere of relaxation and leisure, a meeting of equals and pleasant experiences. Since the research subjects see informal education as a field of voluntary activities, the young people participating in it develop a real commitment to it. There is a wide range of activities and this increases the chances of realizing the personal potential of each individual and even of reinforcing self-esteem (Kahana, 1997).

The terminology of the research participants represents the dominant idea of the theory of education for life (Brubacher, 1966; ) according to which, unlike the modern era, in ancient times there was a close connection between education and life; education dealt with daily issues and enabled young people to integrate into adult society. Then culture became more complex and a need arose for an education system with a curriculum and a staff headed by an expert. As a result, a distance was created between life and education, and hence students' complaints about the relevance of what they study to their real lives. There is a need for a field of education that is parallel to formal education, more relevant to life and that helps young people adjust, solve problems and cope. Formal education seems to be detached, inflexible and non-renewing. Formal education has become a goal and a purpose and there is no connection to the present nor to rejuvenation. On the other hand, informal education is closely connected to the present and to life and its aim is to impart real life experience (Brubacher,1966; Bass \& Eynon, 2016).

However, one can anchor the absolute adherence of the research participants to the theory of cognitive dissonance (Festinger, 1957); people aspire to a balance between attitudes, feelings and actions, and inconsistency between a person's thoughts, feelings and actions may lead to an emotional state that strives to restore that consistency. According to Festinger, all difficult decisions cause dissonance since there will be undesirable features in any decision we opt for, and desirable ones in every option we put aside. Thus, a person who has been guided during his life into a particular professional field will present attitudes that support that choice. Regarding the research, since the participants chose to link their career with informal education, they will tend to present attitudes towards not choosing formal education that will enable them to live with their choice of informal education. However, Festinger also claims that processes of reducing dissonance appear only after an irreversible decision has been made. In this study, most of the subjects were young and so choosing informal education at this point in their professional career is still a decision that can be changed. Post-choice re-evaluation may serve an adaptive purpose by promoting commitment to our selected action, thus preventing us from 
wasting time dwelling on what may have been, and/or getting stuck by constantly changing our minds. Interestingly, enhanced commitment to our chosen options likely occurs when decisions are random, such as blindly sticking a pin in a map to choose a travel destination or flipping a coin to make a life altering decision (Sharot et al, 2010).

From the response of the participants regarding the picture representing formal education, this latter emerges as a strict and rigid institution with an overall negative image. The range of connotations from the pictures above indicates lack of vision and lack of creativity, arousing harsh feelings such as loneliness, sadness and even poverty and boredom. These connotations present the extreme view informal educators have of the formal system in terms of rigidity and being closed: three of the subjects chose warning signs and two chose a bare tree - leafless and fruitless - barren and alone. Another picture is of a pointing finger, the main connotation of which is control and obedience. Two pictures are of an empty classroom with no students, suggesting that the shell is what is important, and two other are of faceless students. For the picture of the square stone on rock, the main connotations are fixation and emptiness. In every picture the absence of any human expression is very prominent.

\section{Conclusions}

From this research, it clearly emerges that the informal educators, through their professional experience as instructors, are certain of the quality of their contribution to the students. They definitely believe that the work methods, contents, tools and the informal code in the informal settings can help students and teachers cope better with the various challenges the education system poses in the realm of society and values and in the realm of motivation and achievements. They see themselves as the basis for a new education system: flexible, open, democratic and pluralistic, one that is the opposite of the formal system which they perceive as stagnant and limiting.

In Israel, recruiting qualified teachers to the formal education system is a problem mainly due to the low status of teaching and the lack of appeal found in the profession. The poor image of the formal teaching system, as seen in this research, shades a new light on the debate of recruiting resourceful and capable teachers to formal education systems in the era of accountability, when the professional work of teachers becomes more and more restricted according to systematic impositions and edicts.

Hence, this research raises the question of recruiting quality teachers to the formal systems by improving teachers' low salaries in Israel (the lowest in OECD scale), developing college programs that involve alternative teaching methods and encouraging excellent students in high school to pursue a teaching career. Further research may study the issues of the Israeli formal education from the learners' point of view.

\section{References}

Barthes, R. (1964). Rhetoric of image. Communications, 4, 1964, pp. 40-51.

Bass, R., \& Eynon, B. (2016). Open and integrative. Washington, DC: Association of American Colleges and Universities.

Ben Galim, N. (2000). Strengthening the professional development of instructors-peers-teachers. Training Teachers, 13, 103-151.

Brubacher, J. S. (1966). A history of the problems of education (translation: Haim Brawer). Tel Aviv: Yachdav Publications.

Cohen, A. (2007). Methodological approaches in the study of informal education. In S. Romi \& M. Shmeida (Eds.), Informal education in a changing reality, (517-543). Jerusalem: School of Education, The Hebrew University.

Coombs, P. H., \& Ahmed, M. (1974). Attacking rural poverty: How non-formal education can help. Baltimore: John Hopkins University Press.

De Saussure, F. (2005) Course in General Linguistics (translation from French - Avner Lahav, according to the 1916 edition of Charles Bally and Albert Sechehaye) Tel Aviv: Resling publications.

\begin{tabular}{|l} 
PROBLEMS \\
OF EDUCATION \\
IN THE 21 $1^{\text {st }}$ CENTURY \\
Vol. 76, No. 3, 2018 \\
\hline 413
\end{tabular}

(n) 
Sara ZAMIR. Appraising the image of formal education by informal educators

\begin{tabular}{r|r} 
PROBLEMS \\
OF EDUCATION \\
IN THE 21 $1^{\text {st }}$ CENTURY \\
Vol. 76, No. 3, 2018 \\
\hline 414
\end{tabular}

Dror, Y. (2006). The history of informal education of youth in pre-state and post-establishment Israel. In S. Romi \& M. Shmeida (Eds.), Informal Education in Israel (7-29). Jerusalem: Magnes.

Festinger, L. (1957). A theory of cognitive dissonance. Stanford, CA: Stanford University Press.

Gal, M. (1985). Informal education in Israel: Random setups or frameworks that fulfill Jewish educational social functions? In: V. Ackerman, A. Carmon \& D.Zucker (Eds.) Education in a Society in Formation (601-666). Tel Aviv and Jerusalem: Hakibbutz Hameuchad and the Van Leer Institute.

Getz, S. (2000). Personal resources, motives for learning and considerations in choosing a profession in various study tracks for a Bachelor degree. Research submitted for approval as a doctoral dissertation. Jerusalem: The Hebrew University.

Gathi, A. (1986). Choosing a course of study and a profession as a decision-making process. Psychology and Counseling in Education, 96, 16.

Kahana, R. (1974). Guidelines for sociological analysis of informal youth organizations. Megamot, 21, 36-46.

Kahana, R. (1975). Assumptions about the structure and roles of informal education setups in modern society. In: Y. Meyuchas (Ed.) Supplementary Education (pp. 45-53). Jerusalem: Ministry of Education and Culture.

Kahana, R. (1997). The origins of postmodern youth -informal youth movements in a comparative perspective. Berlin and New: Walter de Gruyter.

Kahana, R. (20077). Youth and the informal code. Jerusalem: Bialik Institute.

Katzir, Y. Sagi, R., \& Gilat, Y. (2004). Choosing the teaching profession: Types of decision makers and their connection to attitudes towards teaching. Dapim, 38, 10-29.

Keller, D. (1996). Informal education in Israel: Some outlines characterizing its organization and pedagogy. Beit Berl College.

Klivensky, H. (2008). From supplementary education for youth to informal education for all. Mifneh, 17, 33-38 (Hebrew).

Lampert, H. (2009). On the need to abolish the distinction between formal and informal education. MOFET Institute Monthly, 37, 3-4.

Nagar, S. (2001) Choosing the profession of teaching - where to? Maof Uma'ase Mesaper, 7, 1-20.

Romi, S., \& Shmeida, M. (2007a). Informal education in a changing reality. Jerusalem: School of Education, Hebrew University.

Romi, S., \& Shmeida, M. (2007b). A study of informal education in Israel. In Romi, S. \& Shmeida, M. (Eds.), Informal education in a changing reality (pp. 185-190). Jerusalem: Magnes.

Romi, S., \& Shmeida, M. (2007c). The essence of informal education, theoretical approaches and definitions. In: Romi, S. \& Shmeida, M. (Eds.), Informal education in a changing reality (pp. 11-28). Jerusalem: Magnes.

Romi, S. (2009). Informal education: Between establishment and structured temporariness. MOFET Institute Monthly, 37, 18-21.

Sabar Ben-Yehoshua, N. (2006). Traditions and genres in qualitative in qualitative research, Philosophies, strategies and advanced tools. Tel-Aviv: Mofet. (Hebrew).

Silberman-Keller, D. (2007). Outline for professionalization processes in informal education. Dapim, 45, 19-113.

Sharot, T., Velasquez, C. M., \& Dolan, R. J. (2010). Do decisions shape preference? Evidence from blind choice. Psychological Science, 21 (9), 1231-1235.

Received: March 15, 2018

Accepted: June 09, 2018

\section{Sara Zamir}

PhD, Head of School Evaluation Program, Achva Academic College and Ben Gurion University at Eilat, Ness Ziona, 70400 Israel.

E-mail: sarahz@bgu.ac.il 